\title{
Psychological Contract Breach and Turnover Intention: The Intermediary Role of Job Satisfaction
}

\author{
Xiaoqing Xie ${ }^{1}$, Hanmin Liu ${ }^{1}$, Huang Deng² \\ ${ }^{1}$ School of Management, Jinan University, Guangzhou, China \\ ${ }^{2}$ School of Education, Guangxi University, Nanning, China \\ Email: jnuxie@163.com
}

Received 14 September 2015; accepted 9 October 2015; published 12 October 2015

Copyright (C) 2015 by authors and Scientific Research Publishing Inc.

This work is licensed under the Creative Commons Attribution International License (CC BY). http://creativecommons.org/licenses/by/4.0/

c) (7) Open Access

\begin{abstract}
Compared with previous studies, this article, from a dynamic perspective, considers the graduates' expectations for corporate responsibility (CR) and employee responsibility (ER) as virtual psychological contract (PC), and deems the differences between responsibility expectation (RE) and responsibility fulfillment (RF) as psychological contract breach (PCB), for exploring empirically the differences in graduates' perception about PC before and after entering into the workplace, and discussing thoroughly the influence path that PCB acts on job satisfaction (JS) and turnover intention (TI). The results manifest that there are some prominent discrepancies in the cognition about PC, which maybe directly induce graduates' quit. In addition, under the intermediary role of JS, various dimensions of PCB have totally different impacts on TI.
\end{abstract}

\section{Keywords}

Psychological Contract, Psychological Contract Breach, Job Satisfaction, Turnover Intention

\section{Introduction}

As a mutual expectation or understanding existing between organizations and employees, PC is easily influenced by many factors, such as the facilitating or hindering elements within organizations, drastic competition from external environment, and human resources related to the personnel, etc., and then the formation, breach and violation of PC will turn out to be the important stages of dynamic development process about it. More importantly, PC, as an emotional contract, not only is able to satisfy the individual psychological demands, but can continuously and effectively affect their attitudes and behaviors. That is to say, we can quickly find out the main 
reason of graduates' departure and directly tackle some intractable problems by revealing the evolution progress of PC. At present, although the concept, content and structure of PC have been detected maturely, the dynamic study on PC at time point is very limited. Consequently, the dissertation takes a stab at exploring the distinction between graduates' RE before entering the workplace and RF after working in the enterprise, and the influence paths that PCB acts on JS and TI from the perspective of PC.

\section{Literature Review}

PC is a concept which is used to describe the expectation and understanding of the two sides derived from organizations and individuals [1]. Levinson regarded PC as an unwritten contract, which was the sum of the mutual expectation existing between organizations and employees [2]. Later, Kotter et al. extended the domain of PC, and they treated specifically the pay from one side and the reward from the other side. As the result, PC was divided into two dimensions, i.e. individual and organization, which highlighted the interactions existing between employees and enterprises [3]. However, for Rousseau et al., they held the view that employees should be viewed as the cognitive subject of PC rather than enterprises [4].

It's widely accepted that there are two kinds of viewpoints about the structure of PC, two-dimension conception and three-dimension definition. The two-dimension structure of PC was proposed earlier by Macneil, which included "transaction responsibility" factor and "relationship responsibility" factor [5]. Rousseau and Parks believed that although there were a great deal of personalization and distinction in PC, it could be still classified into two categories: transactional PC and relational PC, and there were certain discrepancies between them, for instance, focus of attention, time frame, stability, scope and the degree of certainty [6]. According to Chen's empirical study on the enterprise staff in China, PC could consist of two dimensions: "real responsibility" and "development responsibility" [7]. Nevertheless, Tijoriwala and Rousseau insisted that PC could be measured by gauging its three aspects, "transaction responsibility", "relational responsibility" and "team member responsibility" [8]. Analogously, Li identified the three components of PC, "normative responsibility", "interpersonal responsibility" and "development responsibility", when he conducted a survey in the firms in China [9]. Furthermore, Zhu and Wang put forward the three-dimension structure (including material incentives, environmental supports and development opportunities), which was more in line with the psychological characteristics of Chinese knowledge workers [10].

PC is a kind of emotional relationship easily influenced by the internal and external factors, and presenting a dynamic developing process. It's PCB and Psychological contract violation (PCV) that turn into the two indispensable development stages of PC. On the basis of distinguishing the two concepts, Morrison and Robinson illuminated that PCB was an individual's cognitive evaluation when organization failed to perform their duties, while PCV was a person's emotional experience whose cores were indignation and disappointment [11]. In the academic, a great many scholars have come to a consensus about the relationship among PCB, PCV, employees' attitude and behavior. On the whole, some elementary conclusions can be outlined as follows: 1) PCB has a significant effect on JS, TI and other related variable; 2) JS is related to TI markedly; 3) JS is the mediate variable affecting the relationship between PCB and TI. However, most of authors don't implement the dynamic study at time point, nor did specifically analyze the different influence paths of disparate dimensions of PCB.

In the essay, we stand by the viewpoint of Morrison and Robinson, supposing that PCB and PCV are two completely different notions, and the focus of attention will be concentrated on PCB instead of PCV. Therefore, the present paper manage to ascertain the formation and breach process of PC, and probe into the influence of PCB on JS and TI from the three directions, "responsible party", "structure dimensions", and "dimensions of responsibility”, for the purpose of offering some appropriate opinions and suggestions to figure out the problems of the graduate's quit.

\section{Model and Hypothesis}

Some scholars have recognized that the "non-performance" of PC is the primary reason of PCB [11]. As a consequence, it is imperative to investigate the formation and breach process of the PC and explore the cause-andeffect relationship between PC and other variables.

\subsection{Theoretical Model}

In addition to the formal economic contract, there are certain implicit, informal mutual prospects and hopes be- 
tween organizations and staff, which are also the important determinants affecting employees' attitude and behavior [1]. In other words, the PC is a fundamental emotional contract, which is the subjective feeling of duties and responsibilities shouldered by organizations and employees. So, graduates' expectations for CR and ER before entering the workplace can be regarded as "Virtual PC" which will, to some extent, exert an impact on the formation and breach of PC when they become the constituent parts of enterprises. After working in the organization, the RE of PC will be modified in accordance with the real degree of RF so as to achieve the balance of before and after induction, which could be called "Actual PC". Above analysis, we established a theoretical model, as shown in Figure 1, of formation process reflecting the relationship between "Virtual PC" and "Actual PC".

The imbalance of adjustment rate of CR and ER maybe produce PCB, even PCV. Some scholars have done lots of work, for instance, seeing PCB as the independent variable, JS and organizational commitment (OC) as dependent variables (outcome variables) to look into whether PCB has a prominent impact on JS and OC. The other investigators in organizational behavior, however, assert that JS and OC ought to be treated as mediator variables [12]. For example, By way of an empirical analysis about 804 managers, Feldman and Turnley have verified that job dissatisfaction has a part mediation effect on the relationship between PCB and employee behavior [13]. In this article, under the intermediation of JS, we desire to explore thoroughly the impact of PCB on TI. Based on the above discussion, we constituted a model, as shown in Figure 2, of PCB and its mechanism of action.

\subsection{Research Hypothesis}

Earlier researchers had faith in the two-dimension structure of PC, transaction contract and relational contract. Later scholars were aware of the two-dimension model was not very stable, and easily affected by individual, organizational, social, economic and cultural factors [14]. Since then, numerous scholars have striven to detect the structure of PC under the Chinese culture background, such as the two-dimension or multi-dimension structure. Based on the results of previous studies, we propose the hypothesis and definition about the structure of PC.

HA1: The structure of graduates' perception about PC is composed of three dimensions: transactional responsibility (TR), relational responsibility (RR) and developmental responsibility (DR). Further, TR will be sequentially subdivided into three components: corporate transactional responsibility (CTR), corporate relational

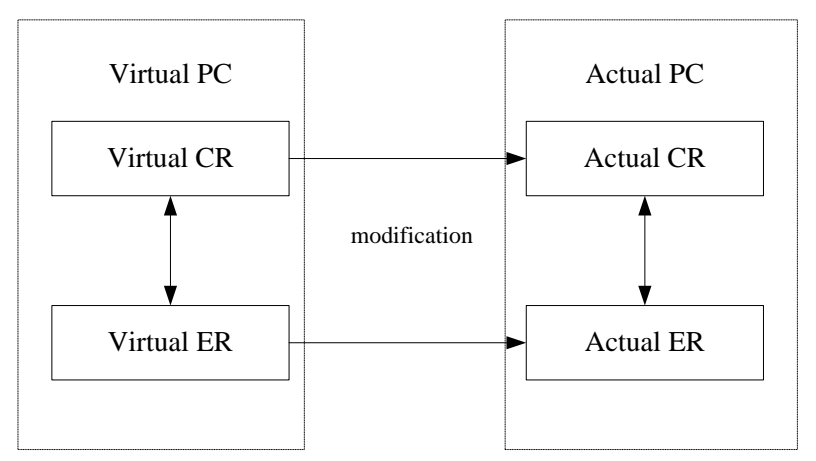

Figure 1. A theoretical model of formation process about PC.

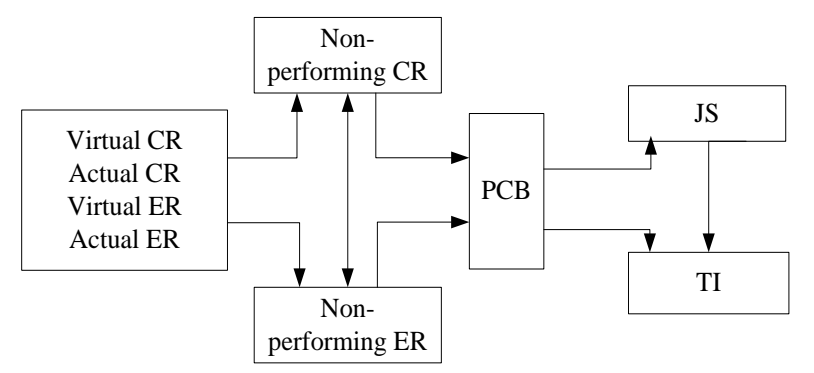

Figure 2. A model of PCB and its mechanism of action. 
responsibility (CRR) and corporate developmental responsibility (CDR); and ER will consist of three components, employee's transactional responsibility (ETR), employee's relational responsibility (ERR) and employee's developmental responsibility (EDR).

Robinson and Morrison, on the basis of a PCV process model, stated that "intentional violation" and "understanding ambiguity" are the source of PCV, and "perceived commitment don't be performed" is the early stage of PCB [11]. Thus it can be seen that the difference between RE and RF is the direct cause of PCB, moreover, the higher expectation, the greater deviations. Not only that, the perception about PCB will become more intense. Thus, the hypothesis can be made as follows.

HB1: There are some conspicuous differences between Virtual PC and Actual PC.

HB2: PCB is dramatically positive correlation with the pre-work RE, significantly negative correlation with the post-work RF.

As mentioned above, the domestic and international scholars assert that the PCB possesses a remarkable impact on the employee's attitudes and behaviors, but it should be tested in the context of Chinese graduates. In addition, there is a great deal of debates about the study results [15] [16]. Accordingly, with the purpose of observing the effect path of PCB acting on employees' attitudes and behaviors, we put forward two hypotheses as follows.

HC1: PCB has an apparent negative effect on JS, and arresting positive effect on TI, and JS has a significant negative effect on TI.

HC2: JS plays a mediation role in the relationship between PC and TI.

The concept of PC is brought forward in the light of social exchange theory and equity theory. And some studies have indicated that the relationship between organizations and staff is mutual, so corporations or employees will transform their behaviors to maintain equilibrium in the transaction [12]. But in the practice of enterprise management, the dynamic adjustment behavior is generally unbalanced, and enterprises are often at the dominant position. So we have plenty of reasons to claim that the main fault of PCB lies in the enterprise, and there are visible distinctions between corporate responsibility breach (CRB) and employee responsibility breach (ERB). The hypothesis can be come up with.

HD1: There are some remarkable differences between CRB and ERB perceived by graduates.

As mentioned above, an increasing number of papers which pay close attention to the relationship among PCB, employee's attitudes and behaviors have been published, but the research achievements about the specific influence path of different dimensions of PCB are very limited. In view of the individual needs of contemporary graduates and the multidimensional attribute of structure of PC, we boldly put forward the view that the different dimensions of PCB, such as "responsibility party", "structural dimension”, and "dimensions of responsibility" will generate different influence path. Thus, the hypothesis can be put forward as follows.

HE1: There are significant differences among the influence paths of different dimensions of PCB.

\section{Research Design and Process}

\subsection{The Questionnaire and Its Modification}

The PC scale was developed on the basis of the two research results: 1) Wei's doctoral dissertation [17]; 2) Li's doctoral thesis [9]. During measurement, we have employed the same terms of questionnaire for two kinds of graduates, and just make little changes about how to raise and answer the questions. There are different ways about how to measure PCB, we adopt the same ways as Robinson did, and operate PCB as follows: PCB = prework responsibility expectation—post-work responsibility fulfillment [18]. In addition, we have developed respectively the questionnaires of JS and TI with reference to the related research works from Quinn et al. and Farth [19]-[22].

In a pretest for 110 graduates in Sichuan and Hubei Province in China, the Cronbach's Alpha and KMO from the subscales are higher than $0.8, P<0.001$, with acceptable reliability and validity.

\subsection{The Test for Reliability and Validity and Confirmatory Factor Analysis}

About the formal investigation of questionnaires, we choose the pre-work 2015 graduating students and the post-work 2014 graduates in China. On the one hand, there are approximately 300 copies which have been distributed to the pre-work graduates, 273 questionnaires were returned but only with 266 valid questionnaires. On 
the other hand, there are about 300 copies which have been distributed to the post-work graduates and a total of 240 copies have been received but only with 235 valid questionnaires. We randomly extract 235 surveys' results as the database of hypothesis testing to facilitate pairing comparison and utilize adequately SPSS 19.0 and AMOS 17.0 software to analyze the data.

After preliminary testing, as is shown in Table 1, the Cronbach's Alpha and KMO of every subscale is greater than $0.8, p<0.001$, and the rate of total variance explained is more than $55 \%$, which proves the favorable reliability and validity. In addition, the evaluation indicators of confirmatory factor analysis (CFA) are in line with the requirements of due, demonstrating the good fitness of three-dimension model about PC. Based on the above analysis results, the PC is a three-dimension structure, and the research hypothesis HA1 is testified.

\section{Hypothesis Testing and Analysis of Results}

By means of designing questionnaire, collecting data and statistical analysis, the research hypotheses which are put forward above can be tested as follows.

First, Paired-Samples T Test is used to verify the graduates' perception differences in the three dimensions of CR and ER. Test results are given in Table 2, as the results display that, the hypothesis HB1 is confirmed partly.

Second, Pearson Correlation Analysis is used to check the relationships among PCB, RE and RF. The test outcome showed by Table 3 illustrates that PCB is positively related to RE, and negatively related to RF. Therefore, the hypothesis HB2 is proved.

Third, Simple Linear Regression Analysis (entry method) is adopted to test the relationship among PCB, JS and TI. The Table 4 reveals that the PCB has an important negative effect on JS, and positive effect on TI. Moreover, JS is significantly negatively related to TI. We may safely draw that the hypothesis HC1 is demonstrated.

Fourth, Hierarchical Regression Analysis is used to discuss the mediating effect of JS. As Table 5 shows, it is evident that PCB has a distinct positive effect on TI $(\beta=0.368, p<0.001)$, but when the JS is introduced into

Table 1. The three-dimension structure model of CR, ER.

\begin{tabular}{cccccccccccc}
\hline & $\mathrm{X}^{2}$ & $\mathrm{DF}$ & $\mathrm{X}^{2} / \mathrm{DF}$ & GFI & AGFI & RMSEA & NNFI & CFI & PNFI & PGFI \\
\hline CR & 118.834 & 75 & 1.584 & 0.941 & 0.905 & 0.050 & 0.961 & 0.972 & 0.664 & 0.588 \\
ER & 86.748 & 49 & 1.77 & 0.947 & 0.901 & 0.057 & 0.946 & 0.966 & 0.582 & 0.510 \\
\hline
\end{tabular}

Table 2. The differences between pre-work graduates and post-work students.

\begin{tabular}{|c|c|c|c|c|c|}
\hline & & $\mathrm{N}$ & Mean & SD & $t$ \\
\hline \multirow{2}{*}{ pairs 1} & Pre-work CTR & 235 & 24.5149 & 3.73291 & \multirow{2}{*}{$14.709^{* * *}$} \\
\hline & Post-work CTR & 235 & 18.6638 & 4.56503 & \\
\hline \multirow{2}{*}{ pairs 2} & Pre-work CRR & 235 & 21.0638 & 3.38425 & \multirow{2}{*}{$10.659^{* * *}$} \\
\hline & Post-work CRR & 235 & 17.7830 & 3.70489 & \\
\hline \multirow{2}{*}{ pairs 3} & Pre-work CDR & 235 & 16.2766 & 2.39927 & \multirow{2}{*}{$15.373^{* * *}$} \\
\hline & Post-work CDR & 235 & 12.1106 & 3.34557 & \\
\hline \multirow{2}{*}{ pairs 4} & Pre-work ETR & 235 & 21.3745 & 2.94323 & \multirow{2}{*}{ 1.320n.s. } \\
\hline & Post-work ETR & 235 & 21.0170 & 3.09530 & \\
\hline \multirow{2}{*}{ pairs 5} & Pre-work ERR & 235 & 19.5574 & 2.89560 & \multirow{2}{*}{ 0.203n.s. } \\
\hline & Post-work ERR & 235 & 19.5021 & 3.00765 & \\
\hline \multirow{2}{*}{ pairs 6} & Pre-work EDR & 235 & 12.1277 & 1.94823 & \multirow{2}{*}{$7.032^{* * *}$} \\
\hline & Post-work EDR & 235 & 10.7404 & 2.41714 & \\
\hline
\end{tabular}

Note: n.s. $p>0.05,{ }^{*} \mathrm{p}<0.05,{ }^{* *} p<0.01,{ }^{* * *} p<0.001$. 
Table 3. The relationship among PCB, RE and RF.

\begin{tabular}{ccccc}
\hline & CRE & CRF & ERE & ERF \\
\hline CRB & $0.637^{* *}$ & $-0.772^{* *}$ & $0.495^{* *}$ & $-0.401^{* *}$ \\
ERB & $0.566^{* *}$ & $-0.369^{* *}$ & $0.678^{* * *}$ & $-0.711^{* *}$ \\
\hline
\end{tabular}

Note: “CRE ‘=’ corporate responsibility expectation”; “CRF ‘=’ corporate responsibility fulfillment”; “ERE ‘=’ employees’ responsibility expectation”; and 'ERF '=' employees' responsibility fulfillment”. n.s. $p>0.05,{ }^{*} p<0.05, \stackrel{* *}{p} p<0.01,{ }^{* * *} p<0.001$.

Table 4. The relationship among PCB, JS and TI.

\begin{tabular}{ccccccccc}
\hline & & \multicolumn{2}{c}{ Standardized regression coefficient } & \multicolumn{4}{c}{ Regression model summary } \\
\cline { 3 - 8 } Independent variable & \multicolumn{2}{c}{ Dependent variable } & $\beta$ & $t$ & $\mathrm{R}$ & $\mathrm{R}^{2}$ & Adjusted $\mathrm{R}^{2}$ & $\mathrm{~F}$ \\
\cline { 3 - 8 } & & -0.393 & $-6.529^{* * *}$ & 0.393 & 0.155 & 0.151 & $42.627^{* * *}$ \\
PCB & JS & 0.368 & $6.048^{* * *}$ & 0.368 & 0.136 & 0.132 & $36.582^{* * *}$ \\
& TI & -0.668 & $-13.715^{* * *}$ & 0.668 & 0.447 & 0.444 & $188.107^{* * *}$ \\
\hline
\end{tabular}

Note: n.s. $p>0.05,{ }^{*} p<0.05,{ }^{* *} p<0.01,{ }^{* * *} p<0.001$.

Table 5. The mediating effect of JS.

\begin{tabular}{|c|c|c|c|c|c|}
\hline \multirow{2}{*}{ Hierarchical variable } & \multirow{2}{*}{ Variables within the hierarchy } & \multicolumn{2}{|c|}{ Hierarchy one } & \multicolumn{2}{|c|}{ Hierarchy two } \\
\hline & & $\beta$ & $t$ & $\beta$ & $t$ \\
\hline Independent variable & РCB & 0.368 & $6.048^{* * *}$ & 0.125 & $2.379^{*}$ \\
\hline Mediating variable & JS & & & -0.619 & $-11.800^{* * *}$ \\
\hline \multirow{4}{*}{ Regression model summary } & $\mathrm{F}$ & \multicolumn{2}{|c|}{$36.582^{* * *}$} & \multicolumn{2}{|c|}{$98.764^{* * *}$} \\
\hline & $\mathrm{R}^{2}$ & \multicolumn{2}{|c|}{0.136} & \multicolumn{2}{|c|}{0.460} \\
\hline & $\Delta \mathrm{F}$ & \multicolumn{2}{|c|}{$36.582^{* * * *}$} & \multicolumn{2}{|c|}{$139.241^{* * *}$} \\
\hline & $\Delta \mathrm{R}^{2}$ & \multicolumn{2}{|c|}{0.136} & \multicolumn{2}{|c|}{0.324} \\
\hline
\end{tabular}

Note: n.s. $p>0.05,{ }^{*} p<0.05,{ }^{* *} p<0.01,{ }^{* * *} p<0.001$.

the regression equation, the impact of PC on TI is significantly reduced (from 0.368 to 0.125 ), which accounts for that the relationship between PCB and TI is partially mediated by JS. Hence, the hypothesis HC2 is tested.

Fifth, T Test is used to analyze the difference between CRB and ERB. As is seen in Table 6, the research hypothesis HD1 is tested.

Sixth, Path Analysis is used to review the different influence paths that PCB acts on JS and TI. The three types of influence paths, that is, "responsibility party", "structural dimensions" and "dimensions of responsibility" have been acquired singly in Figures 3-5.

As is shown in Figure 3, it is obvious that CRB has a negative effect on JS, and JS has a significant negative effect on TI, JS plays an intermediary role in the relationship between CRB and TI; and ERB has a direct positive effect on TI. The result shows: the CR not to be performed will lower employees' JS and indirectly affect TI, but the ER not to be performed may directly result in turnover behavior. As is shown in Figure 4, it is clear that DRB not only has a negative effect on JS, but exert a positive effect on TI, and JS plays an intermediary part in the relationship between DRB, JS and TI. The result shows: 1) The function of DRB is more significant than TRB and RRB. 2) Under the intermediary action of JS, DRB will lower employee JS, thereby affecting the TI, but it may directly influence the turnover behavior. As is shown in Figure 5, it is specific that EDRB has an obvious negative effect on JS, but also has a significant positive effect on TI, and JS plays an intermediary role in the relationship between JS and TI. The result will give evidence of the following conclusions: 1) The function of EDRB is more powerful than CTRB, CRRB, CDRB, ETRB, and ERRB. 2) Under the intermediary action of JS, EDRB will lower employees' JS, and finally affecting the TI, but it may directly affect the turnover behavior. From what has been discussed above, the hypothesis HE1 is sustained fully. 


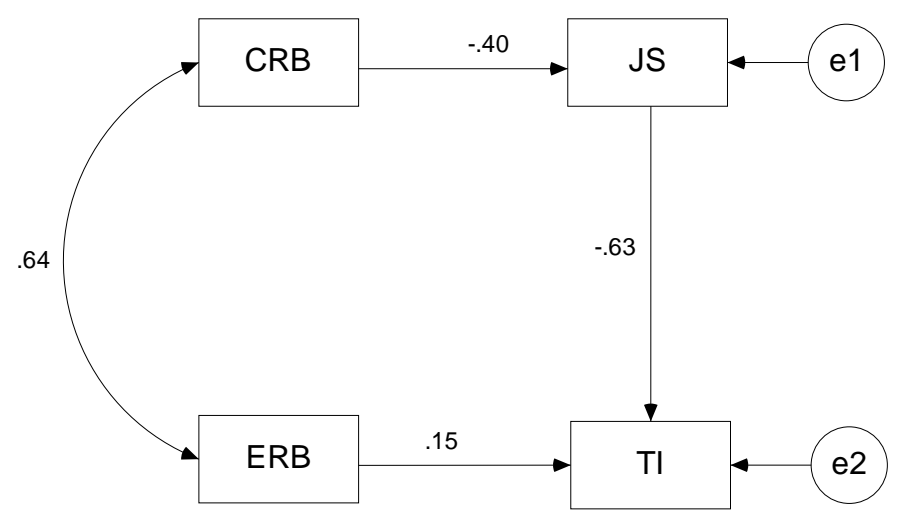

Figure 3. The influence path of "responsibility party” breach. Note: "CRB '=’ corporation responsibility breach”; “ERB '=' employee responsibility breach”. The path whose significance level is less than 0.05 has been deleted.

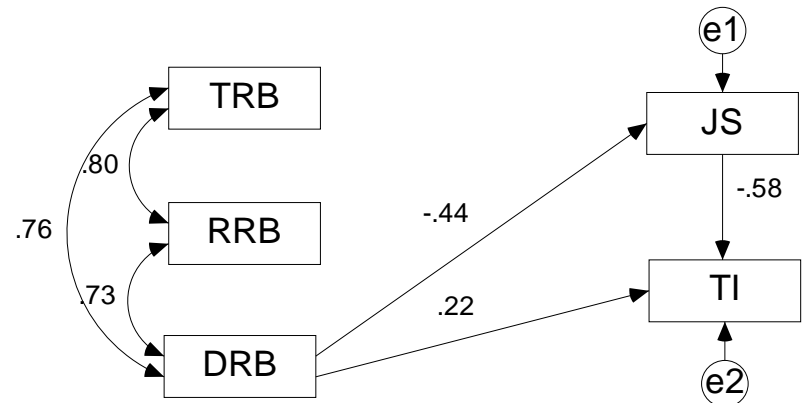

Figure 4. The influence path of "structural dimensions” breach. Note: “TRB '=’ transactional responsibility breach”; “RRB ‘=’ relational responsibility breach”; and "DRB '=' developmental responsibility breach". The path whose significance level is less than 0.05 has been deleted.

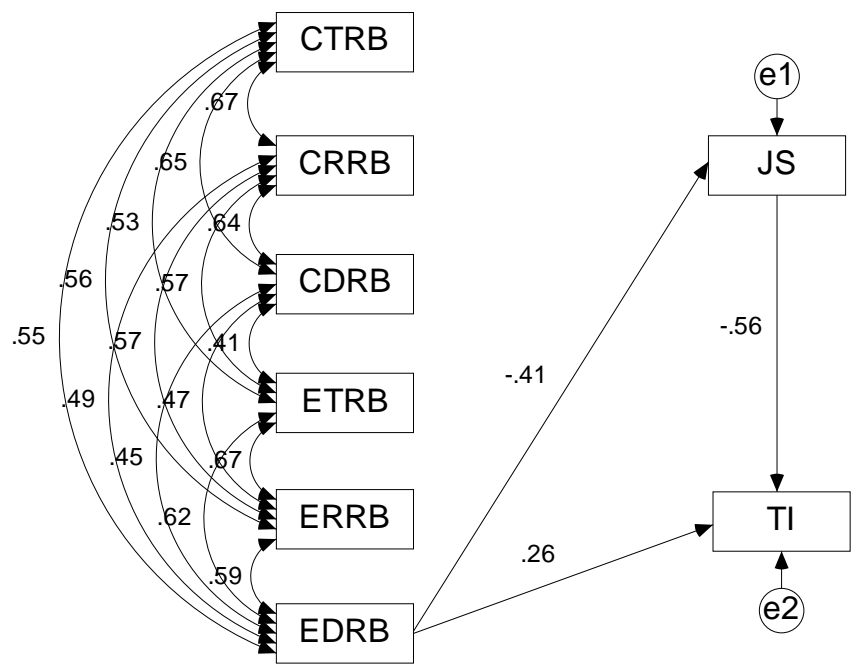

Figure 5. The influence path of "dimensions of responsibility" breach. Note: "CTRB '=' corporations' transactional responsibility breach”; "CRRB '=' corporations' relational responsibility breach”; “CDRB '=' corporations' developmental responsibility breach”; “ETRB '=' employees' transactional responsibility breach”; “ERRB ‘=’ employees’ relational responsibility breach”; “EDRB ‘=’ employees’ developmental responsibility breach". The path whose significance level is less than 0.05 has been deleted. 
Table 6. The difference between CRB and ERB.

\begin{tabular}{ccccc}
\hline & Mean & $\mathrm{N}$ & Standard deviation & $t$ \\
CRB & 13.2979 & 235 & 13.24702 & $17.240^{* * *}$ \\
ERB & 1.8000 & 235 & 9.85354 & \\
\hline
\end{tabular}

Note: n.s. $p>0.05,{ }^{*} p<0.05,{ }^{* *} p<0.01,{ }^{* * *} p<0.001$.

\section{Conclusions and Discussions}

In this paper, we have investigated the relationship between PCB, JS and TI. The main conclusions as follows. First of all, there are certain differences in the perception about the "Virtual PC" and "Actual PC", and the difference is the direct inducement of graduates' quit. Next, the PCB has a striking negative effect on JS, positive effect on TI, and JS has a prominent negative effect on TI and has a partial mediating effect on the relationship between PCB and TI. Again, PC is composed of three dimensions, namely, TR, RR, and DR. Finally, CRB and ERB perceived by graduates are significantly different, the main responsibility of PCB lies in enterprises, the different aspects and dimensions of PCB have different influence path acting on JS and TI.

According to above conclusions, we can obtain some reasonable enlightenment. First, corporations and institutions of high education should shoulder the responsibility of providing employment guidance. Especially, effective and reasonable psychological counseling should be implemented before graduating. Second, it's indispensable for graduates to erect the correct self-positioning. On the one hand, the graduate should be aware that they are suitable for what kind of jobs. On the other hand, they must be acquainted with what kind of talents who enterprises are interested in. Third, enterprises are obligated to "do a good job” to prevent PCB. In an effort to meet the graduates' material demand, meanwhile, enterprises also have to pay attention to graduates' personal characteristics and self-awareness. Fourth, enterprises ought to correctly deal with the problem of graduates' leaving. It's self-evident that, the reason why graduates desert their jobs is complex, changeable, and PCB is just one of the main causes. When dealing with the problem of graduates' turnover, enterprise managers should discard the view that the lost of human resources will cause losses, and be aware of that graduates' appropriate flow is conducive to the optimal allocation of human resources.

\section{References}

[1] Argyris, C. (1961) Understanding Organizational Behavior. Oxford University Press, Oxford, 156-157.

[2] Levinson, H., Molinari, J. and Spohn, A.G. (1972) Organizational Diagnosis. Harvard University Press, Cambridge, 90-95.

[3] Kotter, J.P. (1973) The Psychological Contract: Managing the Joining-Up Process. California Management Review, 15, 91-99. http://dx.doi.org/10.2307/41164442

[4] Rousseau, D.M. (1989) Psychological and Implied Contracts in Organizations. Employee Rights and Responsibilities and Rights Journal, 2, 121-139. http://dx.doi.org/10.1007/BF01384942

[5] Macneil, I.R. (1980) The New Social Contract: An Inquiry into Modern Contractual Relations. Yale University Press, New Haven, 134-137.

[6] Rousseau, D.M. and Parks, I.M. (1993) The Contracts of Individuals and Organizations. Research in Organizational Behavior, 15, 41-43.

[7] Chen, J.Z., Ling, W.Q. and Fang, L.L. (2001) Reviews of Researches on the Psychological Contract in Organizations. Journal of Management Sciences in China, 4, 74-78.

[8] Rousseau, D.M. and Tijioriwala (1996) Perceived Legitimacy \& Unilateral Contract Change: It Takes a Good Reason to Change a Psychological Contract. San Diego Symposium at the SIOP Meetings, San Diago, 289-298.

[9] Li, Y. (2002) The Structure and Related Factors of Employees’ Psychological Contract. Capital Normal University, Beijing.

[10] Zhu, X.M. and Wang, C.M. (2005) The Research on Construct of Knowledge Employees’ Psychological Contract in China. Studies in Science of Science, 23, 118-122.

[11] Morrison, E.W. and Robinson, S.L. (1997) When Employees Feel Betrayed: A Model of How Psychological Contract Violation Develops. Academy of Management Review, 22, 226-256. http://dx.doi.org/10.2307/259230

[12] You, J. (2008) Study on Psychological Contract Violation of the New Employee. Southwestern University of Finance 
and Economics, Chengdu.

[13] Turnley, W.H. and Feldman, D.C. (2000) Re-Examining the Effects of Psychological Contract Violations: Unmet Expectations and Job Dissatisfaction as Mediators. Journal of Organizational Behavior, 21, 25-42. http://dx.doi.org/10.1002/(SICI)1099-1379(200002)21:1<25::AID-JOB2>3.0.CO;2-Z

[14] Chen, J.Z., Ling, W.Q. and Fang, L.L. (2003) Construct Dimension of the Enterprise Staff's Psychological Contract. Acta Psychologica Sinica, 35, 404-410.

[15] Mobley, W.H. (1977) Intermediate Linkages in the Relationship between Job Satisfaction and Employee Turnover. Journal of Applied Psychology, 62, 237-240. http://dx.doi.org/10.1037/0021-9010.62.2.237

[16] Porter, L.W., Pearce, J.L., Tripoli, A.M. and Lewis, K.M. (1998) Differential Perceptions of Employers' Inducements: Implications for Psychological Contracts. Journal of Organizational Behavior, 19, 769-782. http://dx.doi.org/10.1002/(SICI)1099-1379(1998)19:1+<769::AID-JOB968>3.0.CO;2-1

[17] Wei, F. (2004) Study on Psychological Contract Violation between Organizations and Managers. Fudan University, Shanghai.

[18] Robinson, S.L. (1996) Trust and Breach of the Psychological Contract. Administrative Science Quarterly, 41, 574-599. http://dx.doi.org/10.2307/2393868

[19] Quinn, R.P. and Shepard, L.G. (1974) The 1972-1973 Quality of Employment Survey. Institute for Social Research, University of Michigan, Ann Arbor, 90-97.

[20] Pond, S.B. and Geyer, P.D. (1987) Employee Age as a Moderator of the Relation between Perceived Work Alternatives and Job Satisfaction. Journal of Applied Psychology, 32, 552-557. http://dx.doi.org/10.1037/0021-9010.72.4.552

[21] Rice, R.W., Gentile, D.A. and McFarlin, D.B. (1991) Facet Importance and Job Satisfaction. Journal of Applied Psychology, 24, 31-39. http://dx.doi.org/10.1037/0021-9010.76.1.31

[22] Farth, J.L., Tsui, A.S., Xin, K. and Chen, B.-S. (1998) The Influence of Relational Demography and Guanxi: The Chinese Case. Organization Science, 9, 471-488. http://dx.doi.org/10.1287/orsc.9.4.471 